\title{
Molecular Design of Interfacially Active Graft Copolymers by Macromonomer Method
}

\author{
Yoshiki Chujo, Toshiaki ShISHINO, Yasuhisa TsuKaHARA, \\ and Yuya YAMASHITA
}

Department of Synthetic Chemistry, Faculty of Engineering, Nagoya University, Furo-cho, Chikusa-ku, Nagoya 464, Japan

(Received August 20, 1984)

\begin{abstract}
Two kinds of amphiphilic graft copolymers, poly(methyl methacrylate)- $g$-poly(2dimethylethylammoniumethyl methacrylate), by replacing the backbone and branch components were prepared by using macromonomer method. The graft copolymers formed micelles to solubilize bibenzyl in water-acetone mixed solvent. The solution properties of these amphiphilic graft copolymers were remarkably changed by their molecular structures. Surface property of poly(methyl methacrylate) films containing these graft copolymers was also examined by measuring contact angles for water.

KEY WORDS Macromonomers / Amphiphilic Graft Copolymers / Micelles / Surface / Contact Angles /
\end{abstract}

A considerable amount of research effort has been made in the area of preparation of tailor-made comb-like graft copolymers in connection with a molecular design of multi phase systems. For this purpose, macromonomer method may be one of the most promising approach. Recently we have been investigating about the synthesis of tailor-made graft copolymers having controlled numbers and length of branches by macromonomer method. ${ }^{1}$ Surface modification of commodity polymers such as poly(methyl methacrylate) or polystyrene can be achieved by using these amphiphilic surface-active graft copolymers. For example, graft copolymers prepared from polystyrene macromonomer and hydrophilic or hydrophobic comonomers were accumulated on the surface of the polymer matrix and were used for permanent modification of the surface of polystyrene. ${ }^{2}$ These surface properties are known to be of significant importance for their applications in adhesives, fibers or coatings.

On the other hand, amphiphilic graft copolymers, which contain both hydrophilic and hydrophobic components, are expected to form micelles in the solution. It has been recognized that synthetic surfactants could aggregate reversibly to form globular or elongated micelles. The colloidal properties of these amphiphiles may be changed by their molecular structures. For example, Price reported the association behaviour of block copolymers in organic solvents compared with the behaviour of synthetic surfactants in water. ${ }^{3}$ Recently, Gallot reported the difference of solution properties to form micelles between block and graft copolymers. ${ }^{4}$

Here we want to clarify the effect of molecular structure of the graft copolymers, especially the difference between backbone and branches on their solution properties. We wish to report the synthesis of two kinds of amphiphilic graft copolymers by replacing the backbone and the branch components by macromonomer method and the examination of their colloidal property to form micelles.

\section{RESULTS AND DISCUSSION}

Two kinds of amphiphilic graft copolymers, poly(methyl methacrylate)-g-poly(2-dimethylethylammoniumethyl methacrylate) (4 and 8 ), were prepared by macromonomer method as shown in Scheme 1.

Radical polymerization of methyl methacrylate was carried out in the presence of thioglycolic acid 
Y. CHujo et al.
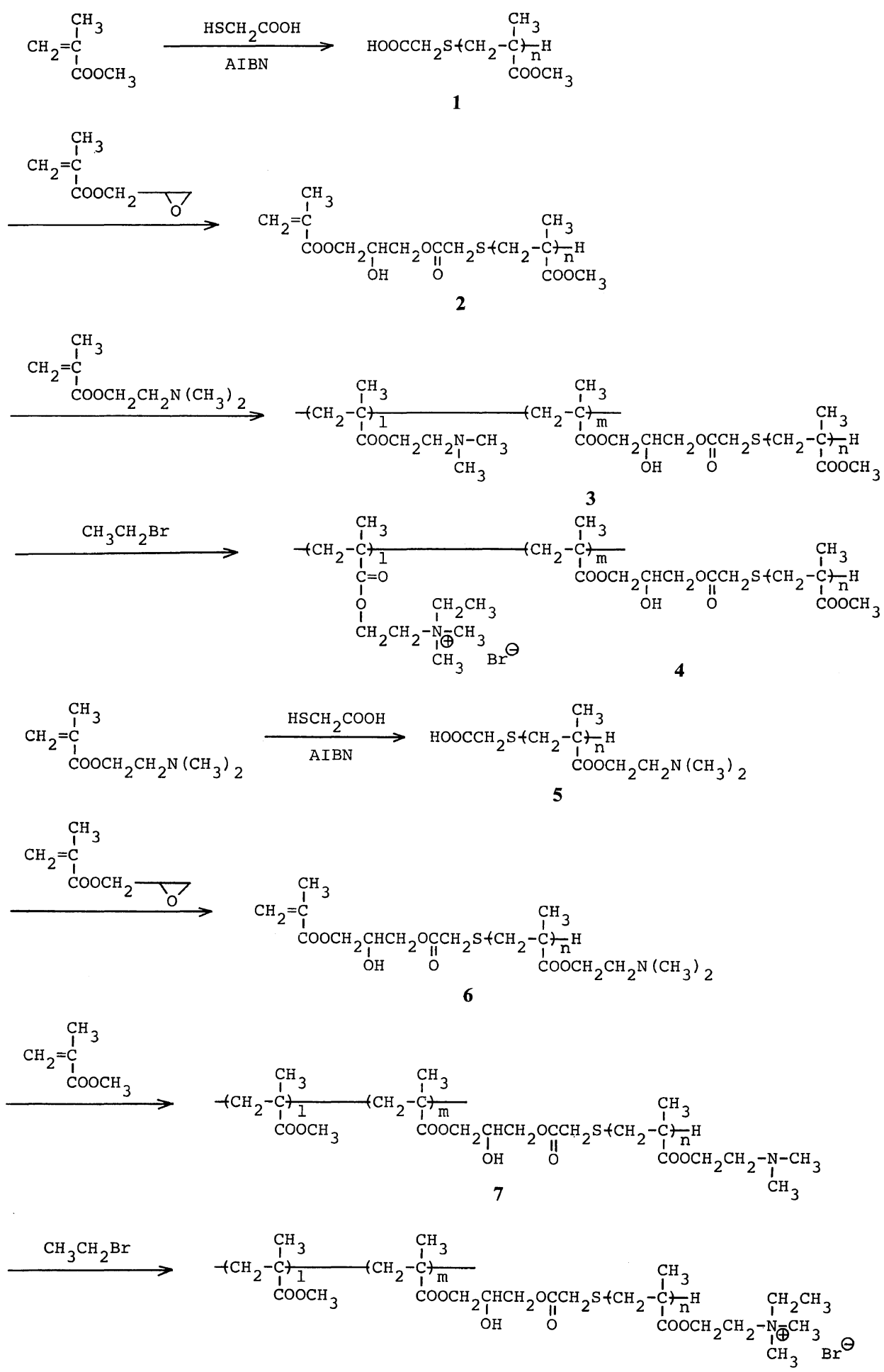

Scheme 1. 
Table I. Preparation of prepolymer (1) and macromonomer (2)

\begin{tabular}{|c|c|c|c|c|c|c|c|c|c|c|c|c|c|}
\hline \multirow{2}{*}{ Polymer } & \multirow{2}{*}{$\frac{\text { MMA }}{\mathrm{g}}$} & \multirow{2}{*}{$\frac{\text { TGA }}{\mathrm{g}}$} & \multirow{2}{*}{$\frac{\mathrm{THF}}{\mathrm{ml}}$} & \multirow{2}{*}[\mathrm{S}]{$_{0} /[\mathrm{M}]_{0}$} & \multirow{2}{*}{$\frac{\text { Temp }}{{ }^{\circ} \mathrm{C}}$} & \multirow{2}{*}{$\frac{\text { Time }}{\mathrm{h}}$} & \multirow{2}{*}{$\frac{\text { Conv. }}{\%}$} & \multicolumn{3}{|c|}{$M_{n}$} & \multirow{2}{*}{$M_{w} / M_{n}$} & \multirow{2}{*}{$\bar{P}_{n}$} & \multirow{2}{*}{$C_{\mathrm{s}}^{\mathrm{b}}$} \\
\hline & & & & & & & & VPO & Tit. & GPC & & & \\
\hline 1 & 100 & 4.52 & 100 & 0.049 & 60 & 2.5 & 39.7 & 3690 & 3550 & 2800 & 1.5 & 35.9 & 0.5 \\
\hline \multicolumn{14}{|c|}{$\begin{array}{l}\text { a }[\mathrm{S}]=[\mathrm{TGA}](\text { thioglycolic acid }) .[\mathrm{M}]=[\mathrm{MMA}](\text { methyl methacrylate }) . \text { AIBN }\left(\alpha, \alpha^{\prime} \text {-azobisisobutyronitrile), } 1 \mathrm{~mol} \%\right. \\
\text { b } C_{\mathrm{s}}=\log \left(1-\alpha[\mathrm{M}]_{0} / n[\mathrm{~S}]_{0}\right) / \log (1-\alpha) . \alpha, \text { conversion; } n \text {, degree of polymerization. }\end{array}$} \\
\hline \multirow{2}{*}{ Polymer } & 1 & GMA & \multirow{2}{*}{\multicolumn{2}{|c|}{$[\mathrm{GMA}] /[\mathbf{1}]$}} & Xylene & Temp & Time & Yield & Conv. & & $M_{n}$ & \multirow{2}{*}{\multicolumn{2}{|c|}{$M_{w} / M_{n}$}} \\
\hline & $\mathrm{g}$ & $\mathrm{g}$ & & & g & ${ }^{\circ} \mathrm{C}$ & $\mathrm{h}$ & $\%$ & $\%$ & VPO & GPC & & \\
\hline 2 & 37 & 3.08 & & 2.1 & 74.7 & 140 & 6 & 96 & 90.1 & 3530 & 2710 & & \\
\hline
\end{tabular}

c GMA, (glycidyl methacrylate).

d Conversion from 1 .

Table Il. Preparation of graft copolymers (3)

\begin{tabular}{|c|c|c|c|c|c|c|c|c|c|}
\hline \multirow{3}{*}{ Run } & \multicolumn{4}{|c|}{ Feed } & \multicolumn{5}{|c|}{ Graft copolymers } \\
\hline & \multirow{2}{*}{$\frac{\mathrm{DM}^{\mathrm{a}}}{\mathrm{wt} \%}$} & \multicolumn{2}{|r|}{2} & \multirow{2}{*}{$\frac{\mathrm{AIBN}}{\mathrm{mol} \%}$} & \multicolumn{2}{|c|}{ GPC } & \multicolumn{2}{|c|}{$w t \% b$} & \multirow{2}{*}{$\begin{array}{c}\text { Number of } \\
\text { branches }\end{array}$} \\
\hline & & $\mathrm{wt} \%$ & $M_{n}\left(\times 10^{-3}\right)$ & & $M_{n}\left(\times 10^{-3}\right)$ & $M_{w} / M_{n}$ & $\mathrm{DM}$ & MMA & \\
\hline 1 & 40 & 60 & 3.53 & 0.19 & 32.4 & 1.7 & 53 & 47 & 4.3 \\
\hline 2 & 40 & 60. & 3.53 & 0.21 & 77.1 & 2.8 & 50 & 50 & 11 \\
\hline
\end{tabular}

a DM (2-dimethylaminoethyl methacrylate).

b Determined from ${ }^{1} \mathrm{H}$ NMR spectra.

c Calculated from the composition and molecular weight of the copolymers.

as a chain transfer agent followed by the reaction of end carboxyl group with glycidyl methacrylate to produce poly(methyl methacrylate) macromonomer (2). Table I shows the results of the preparation of $\mathbf{1}$ and 2. The molecular weight of 1 determined by VPO was 3690 , which was close to that by titration. This result indicates that the functionality of end carboxyl group of $\mathbf{1}$ is 1.04 . The conversion from $\mathbf{1}$ to 2 was almost quantitative by the result of titration of remained end carboxyl groups in $\mathbf{2}$. 1 and 2 have very similar solubilities as the ordinary poly(methyl methacrylate) to be soluble in acetone and insoluble in water.

2 was copolymerized with 2-dimethylaminoethyl methacrylate to give the comb-like graft copolymers (3) consisting of poly(2-dimethylaminoethyl methacrylate) backbone and poly(methyl methac- rylate) branches. The preparation of 3 are summarized in Table II. In this copolymerization reaction, the high concentration of $\mathbf{2}$ and comonomer or bulk polymerization caused the gelation of the products. Unreacted $\mathbf{2}$ or homopolymer of 2 dimethylaminoethyl methacrylate were removed by repeated reprecipitation. This purification process was supported by GPC analysis.

3 was allowed to react with ethyl bromide for quaternization of tertiary amino groups. These conversions were monitored by IR and ${ }^{1} \mathrm{H}$ NMR spectroscopies. IR spectrum of 4 showed the characteristic bands due to ammonium group. As shown in Figure 1, dimethylamino protons ( $\delta 2.2 \mathrm{ppm})$ have disappeared and dimethylammonium protons $(\delta 3.3 \mathrm{ppm})$ appeared in $\mathbf{4}$ during the quaternization. 

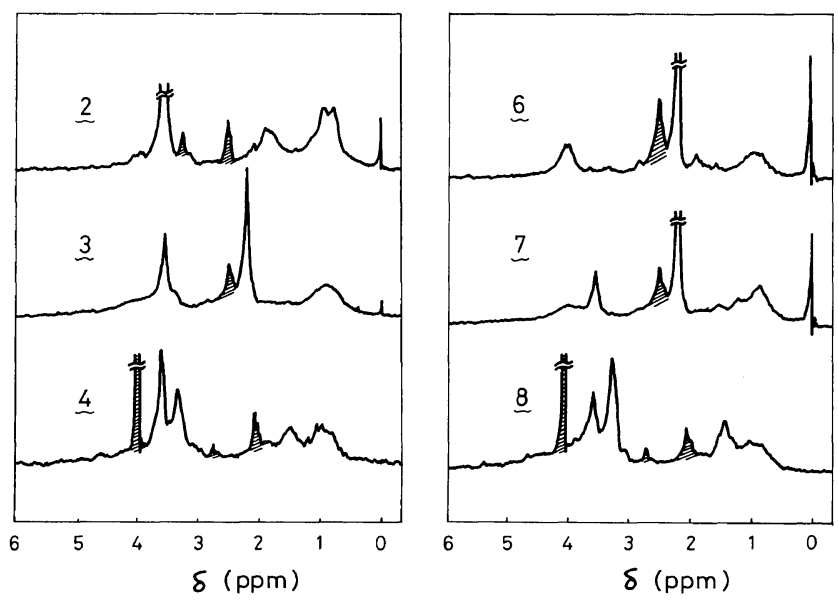

Figure 1. ${ }^{1} \mathrm{H}$ NMR spectra of macromonomers $(\mathbf{2}, \mathbf{6})$ and graft copolymers $(\mathbf{3}, \mathbf{4}, \mathbf{7}, \mathbf{8})$. Hatched peaks and due to solvents.

Table III. Preparation of prepolymers (5) and macromonomers (6) ${ }^{\mathrm{a}}$

\begin{tabular}{|c|c|c|c|c|c|c|c|c|c|c|c|c|}
\hline \multirow{2}{*}{ Polymer } & \multirow{2}{*}{ No. } & \multirow{2}{*}{$\frac{\mathrm{DM}}{\mathrm{g}}$} & \multirow{2}{*}{$\frac{\text { TGA }}{\mathrm{g}}$} & \multirow{2}{*}{$\frac{\mathrm{THF}}{\mathrm{ml}}$} & \multirow{2}{*}[\mathrm{S}]{$_{0} /[\mathrm{M}]_{0}$} & \multirow{2}{*}{$\frac{\text { Temp }}{{ }^{\circ} \mathrm{C}}$} & \multirow{2}{*}{$\frac{\text { Time }}{\mathrm{h}}$} & \multirow{2}{*}{$\frac{\text { Conv. }}{\%}$} & \multicolumn{2}{|c|}{$M_{n}$} & \multirow{2}{*}{$P_{n}$} & \multirow{2}{*}{$C_{\mathrm{s}}^{\mathbf{b}}$} \\
\hline & & & & & & & & & VPO & Tit. & & \\
\hline \multirow{3}{*}{5} & 1 & 31.5 & 0.58 & 31.2 & 0.032 & 60 & 2.5 & 39.0 & 4890 & 2820 & 30.5 & 1.0 \\
\hline & 2 & 31.6 & 0.93 & 31.3 & 0.050 & 60 & 2.5 & 52.8 & 3140 & 4710 & 19.4 & 1.0 \\
\hline & 3 & 31.7 & 0.86 & 31.8 & 0.046 & 60 & 2.5 & 60.4 & 3780 & 3330 & 23.5 & 0.88 \\
\hline
\end{tabular}

${ }^{\mathrm{a}}[\mathrm{S}]=[\mathrm{TGA}]$ (thioglycolic acid), $[\mathrm{M}]=[\mathrm{DM}]$ (2-dimethylaminoethyl methacrylate), AIBN, $1 \mathrm{~mol} \%$.

${ }^{\mathrm{b}} C_{\mathrm{s}}=\log \left(1-\alpha[\mathrm{M}]_{0} / n[\mathrm{~S}]_{0}\right) / \log (1-\alpha)$. $\alpha$, conversion; $n$, degree of polymerization.

\begin{tabular}{|c|c|c|c|c|c|c|c|c|c|c|c|c|c|}
\hline \multirow{2}{*}{ Polymer } & \multirow{2}{*}{ No. } & \multicolumn{2}{|c|}{5} & \multirow{2}{*}{$\frac{\mathrm{GMA}^{\mathrm{c}}}{\mathrm{g}}$} & \multirow{2}{*}[\mathrm{GMA}]{$/[\mathbf{5}]$} & \multirow{2}{*}{ Solvent } & \multirow{2}{*}{$\mathrm{g}$} & \multirow{2}{*}{$\frac{\text { Temp }}{{ }^{\circ} \mathrm{C}}$} & \multirow{2}{*}{$\frac{\text { Time }}{h}$} & \multirow{2}{*}{$\frac{\text { Yield }}{\%}$} & \multirow{2}{*}{$\frac{\text { Conv. }^{\mathrm{e}}}{\%}$} & \multirow{2}{*}{$\frac{M_{n}}{\mathrm{VPO}}$} & \multirow{2}{*}{ Cat. ${ }^{\mathrm{f}}$} \\
\hline & & No. & $\mathrm{g}$ & & & & & & & & & & \\
\hline \multirow{5}{*}{6} & 1 & 3 & 5.03 & 0.33 & 1.5 & DMF & 10.0 & 140 & 6 & - & - & 9170 & None \\
\hline & 2 & 3 & 2.33 & 0.20 & 2.0 & Xylene & 4.7 & 140 & 6 & 89 & 41 & 3960 & $\mathrm{~N}$ \\
\hline & 3 & 3 & 2.33 & 0.21 & 2.1 & Diglyme & 4.7 & 140 & 6 & 92 & 45 & 3460 & $\mathrm{~N}$ \\
\hline & 4 & 3 & 2.33 & 0.20 & 2.0 & $\mathrm{MIBK}^{\mathrm{d}}$ & 4.7 & 140 & 6 & 63 & 35 & 4460 & $\mathrm{~N}$ \\
\hline & 5 & 3 & 2.33 & 0.20 & 2.0 & Diglyme & 4.7 & 140 & 6 & 94 & 26 & 3880 & Sn \\
\hline
\end{tabular}

c GMA (glycidyl methacrylate).

d MIBK (methyl isobutyl ketone).

e Conversion from 5.

${ }^{\mathrm{f}} \mathrm{N}, N, N$-dimethyldodecylamine, $\mathrm{Sn}$, dibutyltin dilaurate.

Poly(2-dimethylaminoethyl methacrylate) prepolymers (5) and macromonomers (6) were prepared by the similar method for $\mathbf{1}$ and $\mathbf{2}$ described above. Table III summarizes these results. The molecular weights of 5 were easily controlled by the feed ratio of thioglycolic acid to the mono- mer. The conversion from 5 to 6 was seemingly low due to the side-reactions of epoxy groups with tertiary amino groups especially by using $N, N$-dimethylformamide (DMF) as a solvent. Xylene or diglyme was used as a solvent and nearly $40 \%$ conversion was attained in these cases as 
Table IV. Preparation of graft copolymers (7)

\begin{tabular}{|c|c|c|c|c|c|c|c|c|c|}
\hline \multirow{3}{*}{ Run } & \multicolumn{4}{|c|}{ Feed } & \multicolumn{5}{|c|}{ Graft copolymers } \\
\hline & \multirow{2}{*}{$\frac{\mathrm{MMA}}{\mathrm{wt} \%}$} & \multicolumn{2}{|r|}{6} & \multirow{2}{*}{$\frac{\mathrm{AIBN}}{\mathrm{mol} \%}$} & \multicolumn{2}{|c|}{ GPC } & \multicolumn{2}{|c|}{$\mathrm{wt}^{\mathrm{o}} \mathrm{o}^{\mathrm{a}}$} & \multirow{2}{*}{$\begin{array}{c}\text { Number of } \\
\text { branches }\end{array}$} \\
\hline & & $w t \%$ & $M_{n}\left(\times 10^{-3}\right)$ & & $M_{n}\left(\times 10^{-3}\right)$ & $M_{w} / M_{n}$ & MMA & $\mathrm{DM}$ & \\
\hline 1 & 33.3 & 66.7 & 3.96 & 0.29 & 76.6 & 3.9 & 39 & 61 & 12 \\
\hline 2 & 33.8 & 66.2 & 3.46 & 0.50 & 57.2 & 4.4 & 47 & 53 & 8.8 \\
\hline 3 & 40.0 & 60.0 & 4.46 & 0.48 & 75.8 & 5.2 & 37 & 63 & 11 \\
\hline
\end{tabular}

${ }^{a}$ Determined from ${ }^{1} \mathrm{H}$ NMR spectra.

b Calculated from the composition and molecular weight of the copolymers.

shown in the table.

Table IV shows the results of the preparation of graft copolymers (7) by radical copolymerization of 6 and methyl methacrylate as a comonomer. Quaternization of tertiary amino groups in 7 with ethyl bromide produced the graft copolymer (8). IR and ${ }^{1} \mathrm{H}$ NMR spectra of $\mathbf{8}$ supported the quantitative conversion from 7 to 8. As shown in Figure 1, ${ }^{1} \mathrm{H}-\mathrm{NMR}$ spectrum of $\mathbf{8}$ in $\mathrm{CDCl}_{3}$ showed almost the same characteristic peaks as that of 4 .

Thus, two kinds of amphiphilic graft copolymers by replacing the backbone and the branch components were easily prepared by using macromonomer method.

By using two kinds of graft copolymers with almost same composition (4; Run 2 in Table II and 8; Run 2 in Table IV), solution properties in water system were examined. Bibenzyl was insoluble in acetone-water mixed solvent $(40: 60, \mathrm{v} / \mathrm{v})$ and its ${ }^{1} \mathrm{H}-\mathrm{NMR}$ spectrum showed no peaks for bibenzyl. However, by adding 4 to this system, bibenzyl was solubilized and showed its aromatic and benzylic protons in ${ }^{1} \mathrm{H}$ NMR spectrum as shown in Figure 2. This result indicates that $\mathbf{4}$ incorporated bibenzyl into its hydrophobic area, which consisted of poly(methyl methacrylate) segments and solubilized bibenzyl in water-acetone mixed solvent. This explanation might be illustrated in Figure 3. Graft copolymer (8) also showed the similar effect on the solubilization of bibenzyl.

Figure 4 summarizes the results of ${ }^{1} \mathrm{H}$ NMR spectra for 4 and 8 by changing the composition of the medium (water-acetone). In both cases, increasing water as a solvent, the integrals for methyl protons of carbomethoxy groups $(\delta 3.7 \mathrm{ppm})$ in poly(methyl methacrylate) were decreased com-

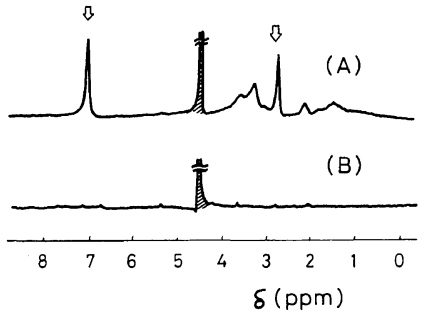

Figure 2. ${ }^{1} \mathrm{H}$ NMR spectra of (A) 4 and bibenzyl and (B) bibenzyl in $\mathrm{D}_{2} \mathrm{O}-\mathrm{CD}_{3} \mathrm{COCD}_{3}(60: 40)$ system. The arrows show the peaks due to bibenzyl.

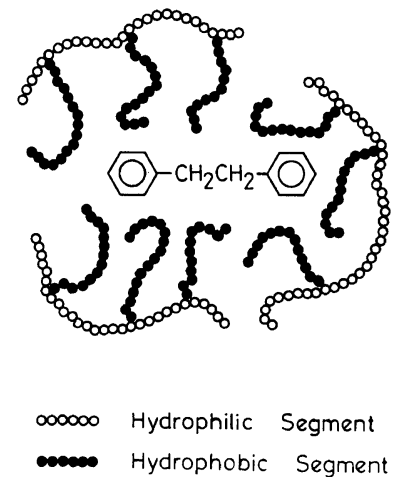

Figure 3. An illustrated model for solubilization of bibenzyl by graft copolymer (4) in water-acetone mixed solvent.

pared with those for dimethylammonium protons ( $\delta 3.4 \mathrm{ppm})$. The integral ratios of these carbomethoxy protons (A) and dimethylammonium protons (B) were plotted against the solvent composition as shown in Figure 5. For the graft copolymer (4), the ratio increased in acetone-rich solvent and decreased in water-rich one. This result shows 

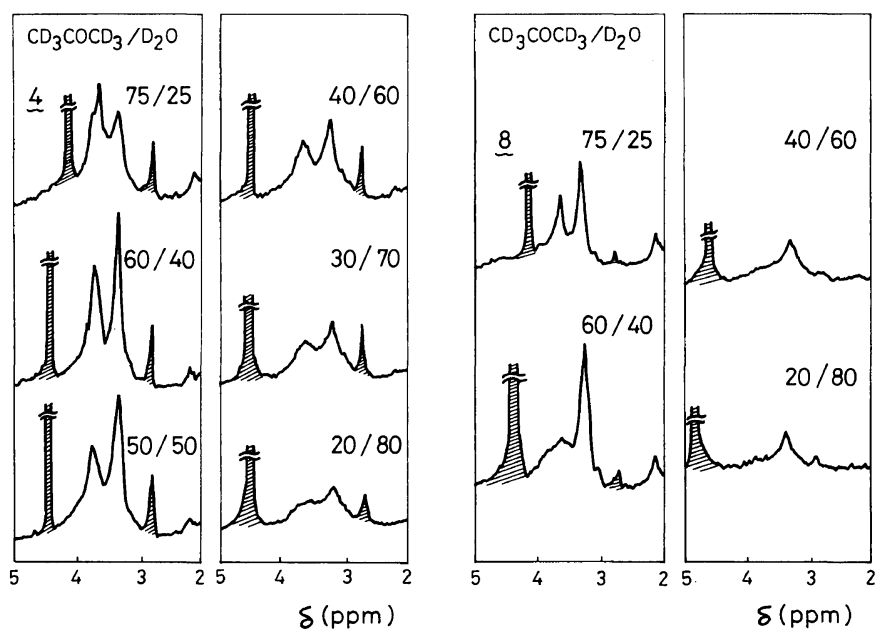

Figure 4. ${ }^{1} \mathrm{H}$ NMR spectra of 4 and 8 in the various composition of water and acetone.

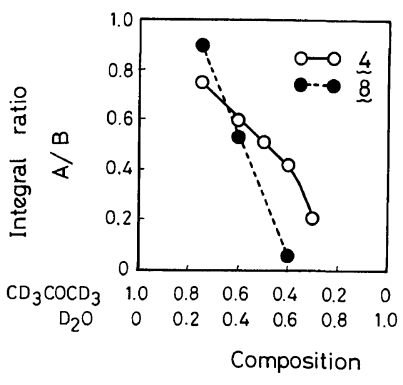

Figure 5. Integral ratios of carbomethoxy protons (A) to dimethylammonium protons (B) in their ${ }^{1} \mathrm{H}$ NMR spectra for 4 and 8 versus rhe composition of solvents.

that hydrophobic poly(methyl methacrylate) segment was relatively immobilized in water-rich medium. That is, $\mathbf{4}$ forms a micelle by the aggregatiton of hydrophobic branches. On the other hand, 8 forms a more rigid micelle in water-rich system from the result of large decrease of the ratio compared with that for 4 . These explanations are illustrated in Figure 6. The micelle from the graft copolymer (8) with hydrophobic backbones was more rigid than that from 4 with hydrophobic branches (Figure 6(b) and (d)). The peak ratio of A to B in Figure 5 was larger than 0.5 in acetone-rich medium, which may show the aggregation of hydrophilic segments and the formation of a kind of reversed micelle as illustrated in Figure 6(a). Figure 7 shows the temperature effect on the peak ratios of A to B for 4 and 8. In acetone-rich solution, the hydrophilic "immo-

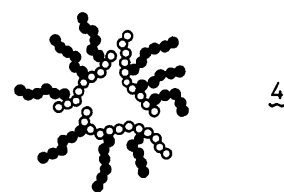

(a)

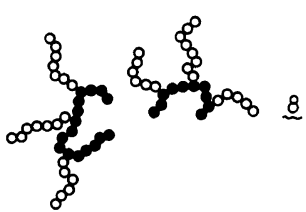

(c)
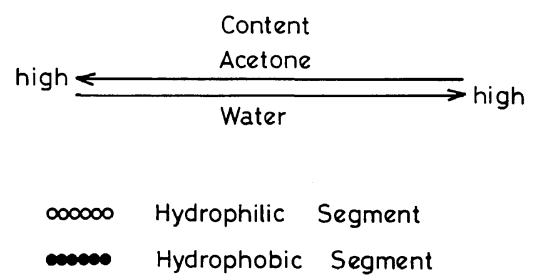

Figure 6. Structural models for the formation of micelles from the graft copolymers (4 and 8) in wateracetone mixed solvent.

bilized" segments in 4 were more mobile by raising the temperature. As a result, the ratio was close to 0.5 . In water-rich solution, the aggregated poly(methyl methacrylate) segments in $\mathbf{4}$ became mobile and the peak ratio increased with the higher temperature. However, 8 in acetone-rich solution 


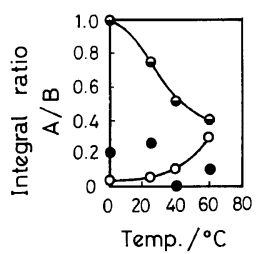

Figure 7. Temperature effect on the integral ratios of A to B: $\ominus ; 4$ in acetone(75)-water(25); $\bigcirc, 4$ in acetone $(50)$-water(50); $\mathbf{0} 8$ in acetone $(75)$-water(25) mixed solvent.

Table V. Reduced viscosities of 4 and 8 in acetone-water system ${ }^{\mathrm{a}}$

\begin{tabular}{ccc}
\hline Solvent & $\mathbf{4}$ & $\mathbf{8}$ \\
\hline Acetone-water & & \\
$60: 40$ & 1.36 & 0.759 \\
$40: 60$ & 1.96 & 0.867 \\
\hline
\end{tabular}

a Measured at $30^{\circ} \mathrm{C}, c=0.400 \mathrm{~g} \mathrm{dl}^{-1}$.

showed no significant changes with the variation of the temperature. This shows that complete micelles were not formed in the case of $\mathbf{8}$ in acetone-rich medium. Because of the low solubility of $\mathbf{8}$ in water-rich solvent, the temperature effect on the formation of micelles could not be examined by ${ }^{1} \mathrm{H}$ NMR spectroscopy. This low solubility might support the very rigid micelles from $\mathbf{8}$ by the aggregation of hydrophobic backbones with star-like structure as shown in Figure 6(d).

Table $\mathrm{V}$ shows the results of the measurement of reduced viscosities of 4 and 8 in acetone-water mixed systems. From these results, the higher association of 4 than 8 in acetone(40)-water(60) and the formation of more rigid micelle from $\mathbf{8}$ in acetone(60)-water(40) were also supported.

In relevance to the solution properties, solid surface properties were also affected by the molecular structure of the graft copolymers. Poly(methyl methacrylate) films containing various amounts of $\mathbf{4}$ or $\mathbf{8}$ were cast from a solution onto clean glass slides. The results of the measurement of contact angles for water are shown in Figure 8. On the glass side of the film, only $1 \mathrm{wt} \%$ of the graft copolymers is sufficient to make poly(methyl methacrylate) surfaces hydrophilic. This behaviour of surface accumulation of the hydrophilic segments for $\mathbf{8}$ was more effective than that for 4 . This result may be

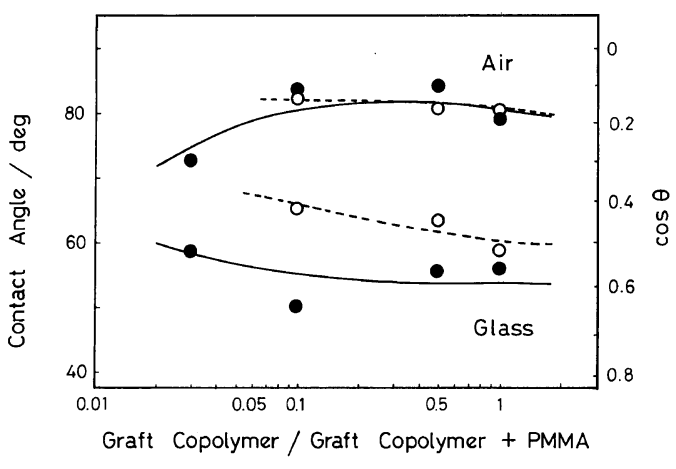

wt $\%$

Figure 8. Contact angles for water of the surfaces of PMMA films containing various amounts of graft copolymers $(\bigcirc, 4 ; 0,8)$.

explained by assuming that the hydrophilic branches in $\mathbf{8}$ is more mobile and arranged effectively on the surface of poly(methyl methacrylate) compared with hydrophilic backbone in 4. This might be correlated with the difference of micelle structure in solution. This interesting effect of the molecular structure of the graft copolymers on surface accumulation is now being investigated and will be reported in a succeeding paper.

\section{EXPERIMENTAL}

\section{Materials}

Methyl methacrylate was washed with $5 \%$ $\mathrm{NaOH}$ aq and $5 \% \mathrm{NaCl}$ aq and dried over $\mathrm{CaH}_{2}$ and distilled under reduced pressure. 2-Dimethylaminoethyl methacrylate was distilled under reduced pressure over $\mathrm{CaH}_{2} . \alpha, \alpha^{\prime}$-Azobisisobutyronitrile was recrystallized from methanol. Thioglycolic acid, glycidyl methacrylate and ethyl bromide were purified by distillation. Bibenzyl was commercially available and used without further purification. All solvents were dried and distilled under a nitrogen atmosphere.

\section{Instruments}

IR spectra were obtained with a JEOL IRA-1. ${ }^{1} \mathrm{H}$ NMR spectra were obtained using a JEOL JNM PMX-60 $(60 \mathrm{MHz})$. GPC was taken on a ToyoSoda HLC-802 UR and calibrated with standard polystyrene samples. Molecular weights by VPO were determined in benzene using a Hitachi-115 instrument. Contact angles of a water droplet were 


\section{Y. Chujo et al.}

measured at $20^{\circ} \mathrm{C}$ by a CA-A type goniometer of Kyowa Kagaku Co., Ltd.

\section{Preparation of PMMA Prepolymer (1)}

In a $500 \mathrm{ml}$ flask equipped with a reflux condenser and a gas inlet cock, methyl methacrylate $(100 \mathrm{~g}$, $1000 \mathrm{mmol})$, AIBN $(1.64 \mathrm{~g}, 9.99 \mathrm{mmol})$, TGA $(4.52 \mathrm{~g}, 49.1 \mathrm{mmol})$ and THF $(100 \mathrm{ml})$ were heated at $60^{\circ} \mathrm{C}$ for $2.5 \mathrm{~h}$ under a nitrogen atmosphere. The prepolymer (1) was isolated as a white powder by precipitation into petroleum ether and purified by reprecipitation and freeze-drying with benzene. Yield was $39.8 \mathrm{~g}(39.7 \%)$. The carboxyl group content was determined by titrating 1 in THF with $0.02 \mathrm{~N}$ aqueous potassium hydroxide, using phenolphthalein as an indicator.

\section{Preparation of PMMA Macromonomer (2)}

$1(37.0 \mathrm{~g}, 10.03 \mathrm{mmol})$, glycidyl methacrylate $(3.08 \mathrm{~g}, 21.7 \mathrm{mmol})$, hydroquinone $(0.023 \mathrm{~g}, 0.209$ mmol) as an inhibitor, $N, N$-dimethyldodecylamine $(0.0309 \mathrm{~g}, 0.145 \mathrm{mmol})$ and xylene $(75 \mathrm{~g})$ were placed in a $500 \mathrm{ml}$ flask and heated at $140^{\circ} \mathrm{C}$ for $6 \mathrm{~h}$. The resulting macromonomer (2) was isolated by precipitation into petroleum ether and purified by reprecipitation and freeze-drying. Yield was $36.9 \mathrm{~g}$ $(96.0 \%)$. The conversion from 1 to 2 was determined by titrating the unreacted carboxyl groups in $\mathbf{2}$.

\section{Preparation of Graft Copolymer (3)}

$2(2.40 \mathrm{~g}, \quad 0.68 \mathrm{mmol}), \quad$ 2-dimethylaminoethyl methacrylate $(1.59 \mathrm{~g}, 10.1 \mathrm{mmol}), \operatorname{AIBN}(0.0037 \mathrm{~g}$, $0.023 \mathrm{mmol})$ and DMF $(20 \mathrm{~g})$ were placed and sealed under vacuum in a glass ampoule. Copolymerization was carried out at $60^{\circ} \mathrm{C}$ for $120 \mathrm{~h}$. The resulting reaction mixture was poured into petroleum ether-diethyl ether $(3: 2, \mathrm{v} / \mathrm{v})$ mixed solvent. Graft copolymer (3) was purified by reprecipitation and Soxlet extraction with diethyl ether. Yield of white powder (3) was $3.61 \mathrm{~g}$.

\section{Quaternization of $\mathbf{3}$ with Ethyl Bromide}

In a $30 \mathrm{ml}$ flask equipped with a reflux condenser and a dropping funnel, graft copolymer (3) $(0.990 \mathrm{~g})$ and DMF $(5.40 \mathrm{~g})$ were placed under a nitrogen atmosphere. From a dropping funnel, ethyl bromide $(0.571 \mathrm{~g}, 5.24 \mathrm{mmol})$ and DMF $(4.57 \mathrm{~g})$ were added at room temperature and the reaction mixture was heated at $50^{\circ} \mathrm{C}$ for $48 \mathrm{~h}$. White powder of 4 was isolated by precipitation into diethyl ether and purified by reprecipitation. Yield was $1.10 \mathrm{~g}$.

\section{Preparation of PDM Prepolymer (5)}

5 was prepared by the same procedure as for 1 starting from $31.7 \mathrm{~g}(202 \mathrm{mmol})$ of 2-dimethylaminoethyl methacrylate. The resulting reaction mixture was poured into petroleum ether at $0^{\circ} \mathrm{C}$. 5 was purified by reprecipitation and washing with petroleum ether. Yield was $19.06 \mathrm{~g}(60.4 \%)$. The carboxyl group content was determined by titration of 5 in a mixed solvent of benzene-methanol $(9: 1, \mathrm{v} / \mathrm{v})$ with $0.02 \mathrm{~N} \mathrm{CH}_{3} \mathrm{OK}$ solution in benzene-methanol under a nitrogen atmosphere.

\section{Preparation of PDM Macromonomer (6)}

In a glass ampoule, $5(2.33 \mathrm{~g}, 0.70 \mathrm{mmol})$, glycidyl methacrylate $(0.21 \mathrm{~g}, 1.48 \mathrm{mmol})$, hydroquinone $(0.0020 \mathrm{~g}, 0.018 \mathrm{mmol}), N, N$-dimethyldodecylamine $(0.0206 \mathrm{~g}, 0.0965 \mathrm{mmol})$ and diglyme $(4.66 \mathrm{~g})$ were placed and sealed under vacuum. After heating at $140^{\circ} \mathrm{C}$ for $6 \mathrm{~h}, 6$ was isolated and purified by the same procedure for 5 . Yield was $2.08 \mathrm{~g}(89 \%)$.

\section{Preparation and Quaternization of Graft Copolymer}

Same procedure was applied for the preparation and quaternization with ethyl bromide of 7 as that for 3 .

\section{Measurement of Contact Angles for Water}

Poly(methyl methacrylate) films containing various amounts of the copolymer $(0-1 \mathrm{w} / \mathrm{w} \%)$ were prepared by casting $2 \mathrm{w} / \mathrm{v} \%$ THF-methanol $(9: 1$, $\mathrm{v} / \mathrm{v})$ solution on clean glass slides, evaporating the solvent overnight and drying in vacuo. Contact angles of water on the air- and glass-sides of the films were measured at $20^{\circ} \mathrm{C}$.

\section{REFERENCES}

1. K. Ito, N. Usami, and Y. Yamashita, Macromolecules, 13, 216 (1980); Y. Yamashita, J. Appl. Polym. Sci., Appl. Polym. Symp., 36, 193 (1981); Y. Yamashita, Y. Tsukahara, K. Ito, K. Okada, and Y. Tajima, Polym. Bull., 5, 335 (1981); Y. Yamashita, Y. Chujo, H. Kobayashi, and Y. Kawakami, Polym. Bull., 5, 361 (1981); Y. Kawakami, Y. Miki, T. Tsuda, R. A. N. Murthy, and Y. Yamashita, Polym. J., 14, 913 (1982); Y. Chujo, T. Tatsuda, and Y. Yamashita, Polym. Bull., 
Interfacially Active Graft Copolymers

8, 239 (1982); Y. Chujo, T. Shishino, and Y. Yamashita, Polym. J., 16, 495 (1984).

2. Y. Yamashita, K. Ito, H. Mizuno, and K. Okada, Polym. J., 14, 255 (1982).
3. C. Price, Pure Appl. Chem., 55, 1563 (1983).

4. J. Selb and Y. Gallot, Makromol. Chem., 181, 2605 (1980); idem., ibid., 182, 1491 (1981); idem., ibid., 182, 1513 (1981); idem., ibid., 182, 1775 (1981). 